\title{
Extracorporeal Membrane Oxygenation for Acute Toxic Inhalations: Case Reports and Literature Review
}

\author{
Dun Yu ${ }^{1 \dagger}$, Zhang Xiaolin ${ }^{2 \dagger}$, Pan Lei ${ }^{2 \dagger}$, Li Feng ${ }^{2 \star}$, Zhang Lin ${ }^{1,3 *}$ and Shen Jie ${ }^{1,3 *}$ \\ ${ }^{1}$ Department of Emergency and Critical Care Medicine, Jinshan Hospital, Fudan University, Shanghai, China, ${ }^{2}$ Department of \\ Respirology, Shanghai Public Health Clinical Center, Fudan University, Shanghai, China, ${ }^{3}$ Department of Critical Care \\ Medicine, Medical Research Center of Chemical Injury, Jinshan Hospital, Fudan University, Shanghai, China
}

\section{OPEN ACCESS}

Edited by:

Yih Sharng Chen,

National Taiwan University Hospital, Taiwan

Reviewed by:

Giles John Peek,

University of Florida, United States

Ying Zhu,

Hangzhou First People's

Hospital, China

${ }^{*}$ Correspondence:

Li Feng

lifeng@shphc.org.cn

Zhang Lin

linzhang0315@fudan.edu.cn

Shen Jie

j1999sh@163.com

†These authors have contributed equally to this work

Specialty section: This article was submitted to Intensive Care Medicine and Anesthesiology,

a section of the journal

Frontiers in Medicine

Received: 22 July 2021 Accepted: 02 September 2021 Published: 29 September 2021

Citation:

Yu D, Xiaolin Z, Lei P, Feng L, Lin Z and Jie $S$ (2021) Extracorporeal Membrane Oxygenation for Acute Toxic Inhalations: Case Reports and

Literature Review.

Front. Med. 8:745555.

doi: 10.3389/fmed.2021.745555
Previous studies have shown that poisoning is a major threat to human health. Inhalation of acute toxic gas has been linked to serious health consequences. Among the antidotes for poisoning currently used, supportive care is the most common intervention in clinical practice. Severe acute respiratory distress syndrome (ARDS) and/or refractory cardiogenic shock or cardiac arrest caused by toxins are associated with high mortality and are difficult to treat. Extracorporeal membrane oxygenation (ECMO) is an aggressive supportive measure used to manage severely poisoned patients. This study presents two cases of acute toxic gases inhalation, severe ARDS and circulatory instability induced by bromine inhalation, and ARDS induced by nitric acid inhalation which were successfully treated with ECMO. The ECMO techniques used in the animal models and in human cases to treat severe poisoning are described as well as the indications, contraindications, complications, and weaning of ECMO.

Keywords: extracorporeal membrane oxygenation, acute toxic inhalation, poisoning, ARDS, cardiogenic shock, cardiac arrest

\section{INTRODUCTION}

Poisoning causes a detrimental effect to human health. The 37th Annual Report of American Association of Poison Control Center's (AAPCC) National Poison Data System (NPDS) showed that there were $2,148,141$ cases of human toxicological exposure in 2019. In addition, 2,048 out of 2,619 deaths were identified as exposure-related fatalities whereas 1,688 (81.4\%) of the 2,048 fatalities were identified as drug exposure cases. The main exposure routes were ingestion $(80.1 \%)$, inhalation/nasal (8.15\%), and parenteral (5.24\%). Furthermore, the most human toxic exposures were unintentional (76.6\%) (1). The Centers for Disease Control and Prevention (CDC) reported that the incidence of mortality due to poisoning has been increasing in the past decade (2).

The previous studies define acute toxicity as the adverse effects of a substance resulting either from single or multiple exposures in short periods of time (usually less than $24 \mathrm{~h})(3,4)$. Acute toxic inhalation is considered an emergency in clinical practice. The previous studies have established that smoke, gases, and vapors are the most frequently inhaled substances $(4,5)$. Acute inhalation of toxic substances often occurs during the production, operation, storage, transportation, and other human factors. A National Occupational Exposure Survey (NOES) conducted from 1981 to 1983 estimated that more than 1,000,000 million workers in the United States were at risk of exposure 
to respiratory irritants annually. However, the data from poison control centers have suggested that exposure to the toxic substances occurs more frequently in the home environment than at workplaces (6).

Inhalation of gases, mists, aerosols, fumes, or dust may irritate the lungs, cause acute respiratory distress syndrome (ARDS), asphyxiation, and cardiogenic shock (5). Respiratory failure or cardiogenic shock or cardiac arrest caused by acute toxic inhalation are related to significant mortality (79). Several antidotes have been used to control the damage caused by some toxins, such as hydroxocobalamin for cyanide, fomepizole for methanol, pralidoxime chloride, and atropine for organic phosphorus pesticide poisoning, and oxygen for carbon monoxide. However, such antidotes are not effective in all the cases. Extracorporeal membrane oxygenation (ECMO) is an external device that can provide cardiopulmonary support for patients. The previous studies reported successful use of ECMO in the treatment of severe ARDS $(10,11)$ and refractory cardiogenic shock or cardiac arrest (12-14) following its introduction. The studies have also reported the use of ECMO in both animal models and human cases with refractory shock and/or ARDS induced by intoxication or toxicant exposure (1519). The randomized trials of ECMO in the poisoned patients with acute toxic inhalation have not yet been undertaken. The available evidence has been generated from observational cohorts, case series, and case reports (20). The previous studies have, however, reported that early initiation of ECMO can improve the outcome of severely poisoned patients when optimal conventional treatment failed $(18,21,22)$. Therefore, ECMO is a potential treatment option for patients with acute toxic inhalation with refractory circulatory shock and/or ARDS. The previous studies have shown that ECMO helps in the recovery from acute incidents, or transition to or candidacy for long-term advanced therapies, such as surgical ventricular assist devices or transplants $(14,23,24)$.

In the current study, two successful ECMO support cases for acute toxic gases inhalation with severe ARDS were elaborated. In addition, the current study described the ECMO techniques, an application of ECMO in poisoned patients, indications, contraindications, complications of use, and weaning of ECMO.

\section{CASE REPORTS}

\section{Case 1}

A 44-year-old man, working in a chemical plant, was accidentally exposed to bromine gas $\left(\mathrm{Br}_{2}\right)$. The worker became unconscious for $15 \mathrm{~min}$ and was transferred to an open-air setting by the colleagues, where the man gained consciousness after $10 \mathrm{~min}$.

Upon admission to a local hospital, the man presented with several symptoms, such as dyspnea, vomit, fatigue, cough, pharyngalgia, and mental confusion. The patient remained conscious with the following vital signs: blood pressure 92/63 $\mathrm{mmHg}$, pulse rate 94 beats/min, respiratory rate 22 breaths/min, temperature $36^{\circ} \mathrm{C}$, oxygen saturation (80-85\%) supported by mask ventilator assisted ventilation with inhaled $100 \%$ oxygen concentration. Arterial blood gases obtained before intubation were: $\mathrm{pH}$ 7.309, partial pressure of oxygen $\left(\mathrm{PaO}_{2}\right) 8.18 \mathrm{kpa}$, partial pressure of carbon dioxide $\left(\mathrm{PaCO}_{2}\right) 6.73 \mathrm{kpa}$, and bicarbonate concentration $-0.9 \mathrm{mmol} / \mathrm{L}$ (P/F oxygen ratio was $61.5 \mathrm{mmHg}$ ). Despite inhaling $100 \%$ oxygen, the status of dyspnea did not improve but progressively worsened accompanied with profuse sweating and irritability. Moreover, a pronounced stridor could be heard. The physical examination revealed cyanosis of the lips and mouth, shortness of breath, three concave signs, and increased bilateral vesicular sounds. Because of laryngeal edema caused by $\mathrm{Br}_{2}$ irritation and potential retention of secretions in the lower respiratory tract with a probable need for more than a week of respiratory support, a tracheotomy was performed immediately. A large amount of pinkish foamy secretions was discharged from the patient's mouth after tracheotomy. The clinical and laboratory investigations indicated that the pulse oxygen saturation $\left(\mathrm{SpO}_{2}\right)$ was less than $90 \%$ after assisted mechanical ventilation. A chest $\mathrm{x}$-ray showed pulmonary edema with fluid-filled bilateral lungs (Figure 1). Subsequently, a single dose of methylprednisolone $(80 \mathrm{mg})$ was administered intravenously. Considering the severity of the $\mathrm{Br}_{2}$-induced injury, the patient was transferred to critical care center $4 \mathrm{~h}$ after $\mathrm{Br}_{2}$ inhalation for definitive treatment.

At the critical care center, the patient received synchronized intermittent mandatory ventilation (SIMV), with initial settings of positive end-expiratory pressure (PEEP) of $12 \mathrm{cmH}_{2} \mathrm{O}$, fraction of inspired oxygen $\left(\mathrm{FiO}_{2}\right)$ of 1.0 , respiratory rate $(R R)$ of $16 \mathrm{bpm}$, tidal volume $\left(\mathrm{V}_{\mathrm{T}}\right)$ of $4 \mathrm{ml} / \mathrm{kg}$, and plateau pressure (Pplat) $\leq 25 \mathrm{cmH}_{2} \mathrm{O}$. In addition to the routine critical care, initial management included absolute bed rest, intravenous methylprednisolone, anticoagulation, energy and vitamin supplements, maintenance of water, electrolytes, and acid-base balance. However, the condition of the patient worsened. Arterial blood gases recorded $48 \mathrm{~h}$ after mechanical ventilation were: $\mathrm{pH} 7.26, \mathrm{PaO}_{2} 6.13 \mathrm{kpa}, \mathrm{PaCO}_{2} 4.97 \mathrm{kpa}$, and bicarbonate concentration $2.4 \mathrm{mmol} / \mathrm{L}$ (P/F oxygen ratio was $46 \mathrm{mmHg}$ ). Thereafter, the patient was initiated on ECMO. Two cannulas were placed percutaneously by vessel puncture, guidewire placement, and serial dilation. One cannula (Edward 24F, Edwards Lifesciences Corp., CA, USA) was advanced into the right femoral vein; another (Edward 16F) into the right internal jugular vein. The assembled circuit (PLS heparin-coated ECMO kit, Edward) was primed. Initial ECMO flow settings were: blood flow of $4 \mathrm{~L} / \mathrm{min}$, sweep gas flow of $2 \mathrm{~L} / \mathrm{min}, \mathrm{FiO}_{2}$ of 1.0 , and temperature of the water bath was set at $36.8^{\circ} \mathrm{C}$ (adjusted according to arterial blood gas). The ventilator settings immediately pre-ECMO were: P-SIMV, PEEP $12 \mathrm{cmH}_{2} \mathrm{O}, \mathrm{FiO}_{2}$ 0.5 , RR $8 \mathrm{bpm}, \mathrm{V}_{\mathrm{T}} 4 \mathrm{ml} / \mathrm{kg}$, Pplat $\leq 25 \mathrm{cmH}_{2} \mathrm{O}$. The patient was sedated with fentanyl and midazolam during cannulation and management for the first 12-24h. Richmond AgitationSedation Scale (RASS) was -5 . The neurologic examination was performed daily to ensure that the sedation was sufficient. Once the patient had stabilized on ECMO, all the sedatives and narcotics were stopped and resumed depending on the levels of anxiety and discomfort of the patient. Heparin (50100 units per $\mathrm{kg}$ ) was administered at the time of cannulation and continuously infused during ECMO. Heparin infusion was regulated to keep the activated partial thromboplastin time 


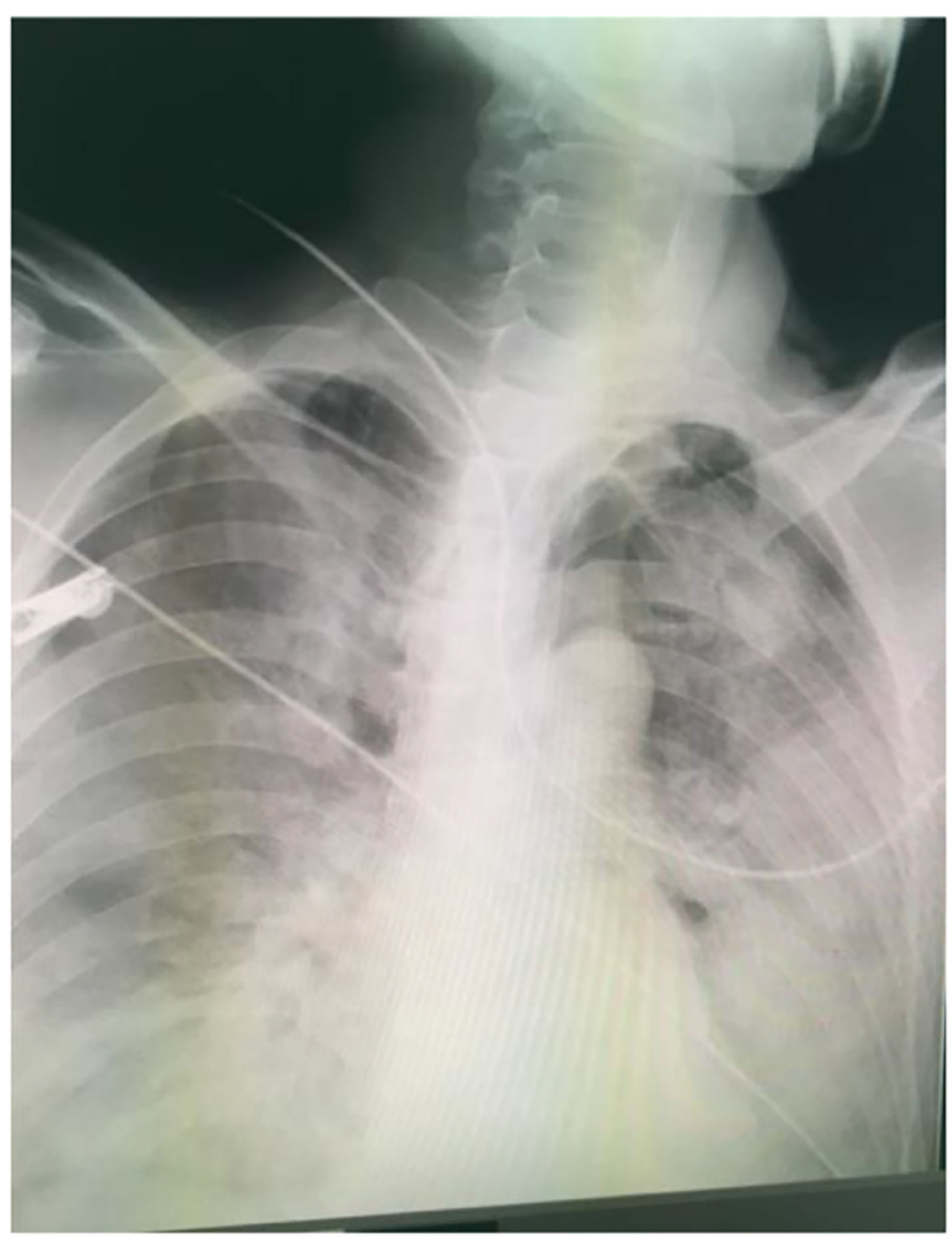

FIGURE 1 | Chest x-ray revealed pulmonary edema with fluid-filled bilateral lungs.

(APTT) at designated levels (usually 1.5 times the normal values for the APTT measurement system). Hemoglobin levels, blood platelet counts, and lactic acid accumulation were regularly detected to monitor the development of complications. The rest settings during ECMO support were: Ppeak 20-25 $\mathrm{cmH}_{2} \mathrm{O}$, PEEP 10-15 $\mathrm{cmH}_{2} \mathrm{O}$, RR $10 \mathrm{bpm}$, and $\mathrm{FiO}_{2}$ 0.4.

In addition to ECMO support, the pharmacologic diuresis and antibiotic treatment were administered. Respiratory parameters of the patient improved and the chest CT images showed that the bilateral infiltrations had regressed after 7 days of therapy. The patient was weaned off ECMO upon shock reversal and attaining stable condition. The arterial blood gases were analyzed when the patient was extubated: $\mathrm{pH}$ 7.47, $\mathrm{PaO}_{2} 98.3$ mmHg, $\mathrm{PaCO}_{2} 38.7$
mmHg, and $\mathrm{SpO}_{2}$ 99\%. The chest CT was performed on 2nd and 7 th day after weaning (Figure 2). It was found that the lung edema had resolved. Follow-up chest CT after discharge from the hospital showed progressive improvement in the affected lung regions.

\section{Case 2}

A 41-year-old man with a history of hepatitis B, who was taking tenofovir disoproxil fumarate drugs, presented with the complaint of chest stuffiness and shortness of breath immediately after inhaling mixed chemical gas during unloading of concentrated nitric acid. The man was generally healthy with a normal hepatic function. However, the serum HBV-DNA level of 


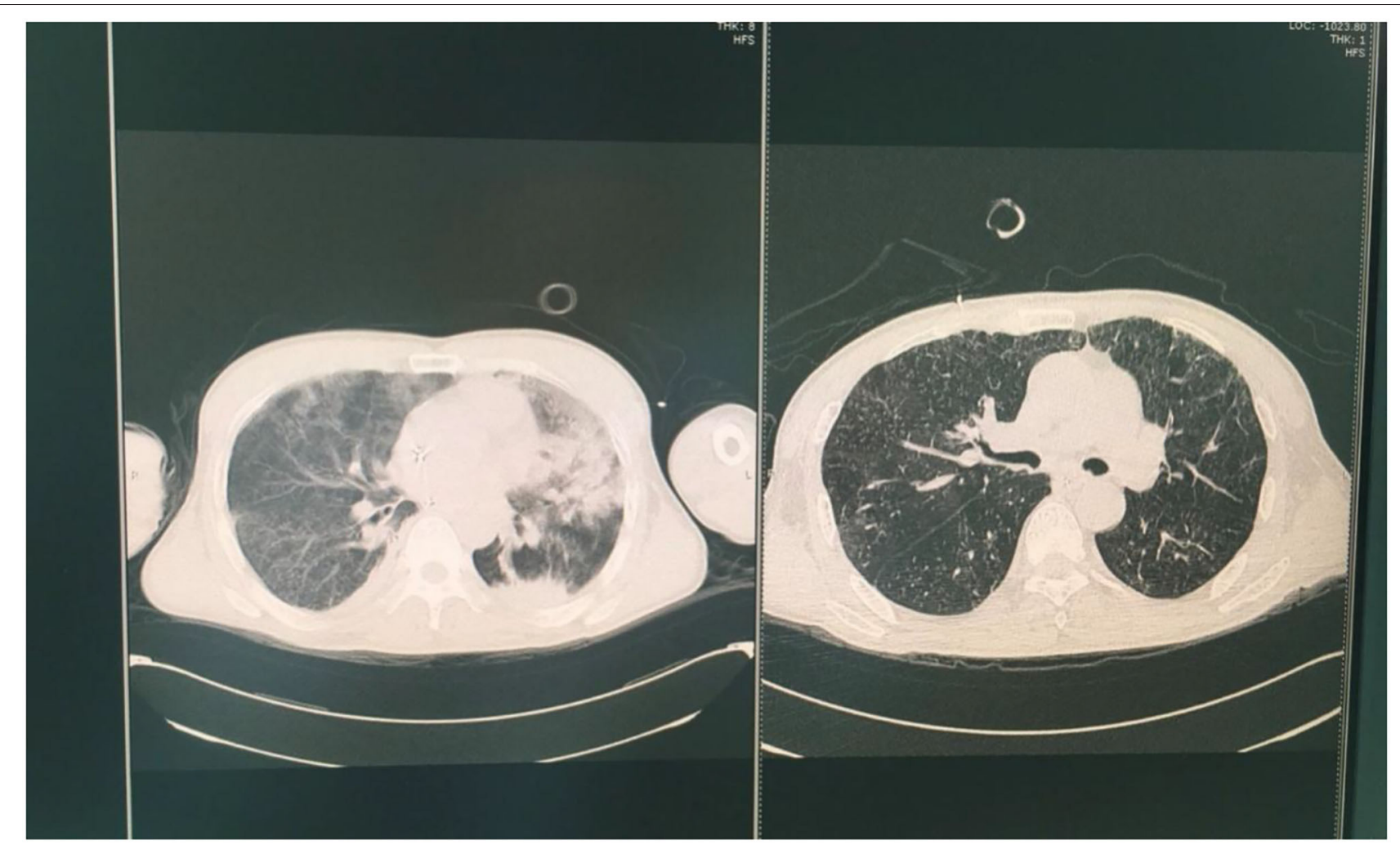

FIGURE 2 | The chest CT images on the second (left) and seventh day (right) after weaning.

this man was lower than the detection limit. Based on the reports from the factory, the mixed gas mainly comprised of $\mathrm{NO}_{2}, \mathrm{NO}$, and $\mathrm{HNO}_{3}$, with a small amount of benzene.

Upon admission to a local hospital, the oxygen saturation was $94 \%$ after receiving nasal cannula oxygenation at a flow rate of $2 \mathrm{~L} / \mathrm{min}$. The symptoms of shortness of breath worsened $2 \mathrm{~h}$ after the nasal cannula oxygenation. Chest CT showed scattered exudation in bilateral lower lungs (Figure 3A). The patient was transferred to a local tertiary hospital where the man received high-flow oxygenation. Non-invasive ventilation was administered $14 \mathrm{~h}$ following the failure of high-flow oxygenation. At $9 \mathrm{~h}$ after admission to the intensive care unit (ICU), the patient was orotracheally intubated and mechanically ventilated due to progressive hypoxemia. However, the partial pressure of oxygen $\left(\mathrm{PaO}_{2}\right)$ dropped to $50 \mathrm{mmHg}(\mathrm{P} / \mathrm{F}$ oxygen ratio was $62.5 \mathrm{mmHg})$ $4.5 \mathrm{~h}$ after mechanical ventilation. Chest $\mathrm{CT}$ showed extensive exudation and pleural effusion in bilateral lungs (Figure 3B). These findings indicated ARDS and veno-venous-ECMO (VVECMO) was performed immediately.

Two cannulas (23-19Fr) were advanced percutaneously via the right femoral vein for drainage and the right internal jugular vein for reinfusion. The assembled circuit (PLS heparincoated ECMO kit, Maquet, Germany) was primed. The initial ECMO flow settings were: blood flow of $4.5 \mathrm{~L} / \mathrm{min}$, sweep gas flow of $4.5 \mathrm{~L} / \mathrm{min}, \mathrm{FiO}_{2}$ of 1.0 , temperature of the water bath was set at $36^{\circ} \mathrm{C}$ (adjusted according to arterial blood gas). The ventilator settings immediately pre-ECMO were: $\mathrm{P}$ SIMV, PEEP $10 \mathrm{cmH}_{2} \mathrm{O}, \mathrm{FiO}_{2}$ 0.3, RR $10 \mathrm{bpm}, \mathrm{V}_{\mathrm{T}} 4 \mathrm{ml} / \mathrm{kg}$, and Pplat $\leq 25 \mathrm{cmH}_{2} \mathrm{O}$. The patient was sedated with remifentanil and midazolam during cannulation and management for the first $12-24 \mathrm{~h}$. RASS was -5 . The neurologic examinations were done daily to ensure that the sedation was sufficient. Heparin (50-100 units per $\mathrm{kg}$ ) was administered at the time of cannulation, and then through continuous infusion during ECMO. Heparin infusion was regulated to keep APTT within designated levels (usually 1.5 times normal for the APTT measurement system). The hemoglobin levels, blood platelet counts, and lactic acid accumulation were measured regularly to monitor the occurrence of complications. The rest settings during ECMO support were: Ppeak 20-25 $\mathrm{cmH}_{2} \mathrm{O}$, PEEP 10-15 $\mathrm{cmH}_{2} \mathrm{O}, \mathrm{RR} 10$ bpm, and $\mathrm{FiO}_{2} 0.4$.

In addition to ECMO, the patient received intravenous methylprednisolone, prone ventilation, and nasogastric gavage with $\mathrm{N}$-acetylcysteine and pirfenidone. The patient was weaned off successfully $71 \mathrm{~h}$ after ECMO support and was extubated $16 \mathrm{~h}$ later. Chest CT (Figure 3C) showed that the diffuse exudation and pleural effusion in bilateral lungs had significantly resolved. The chest CT revealed progressive remission of exudative lesions in bilateral lungs 2 days after weaning (Figure 3D). The patient was discharged from the hospital 4 days after weaning. At 54 days after discharge, a follow-up chest CT showed that the lesions in bilateral lungs had almost resolved (Figure 3E). Lung 


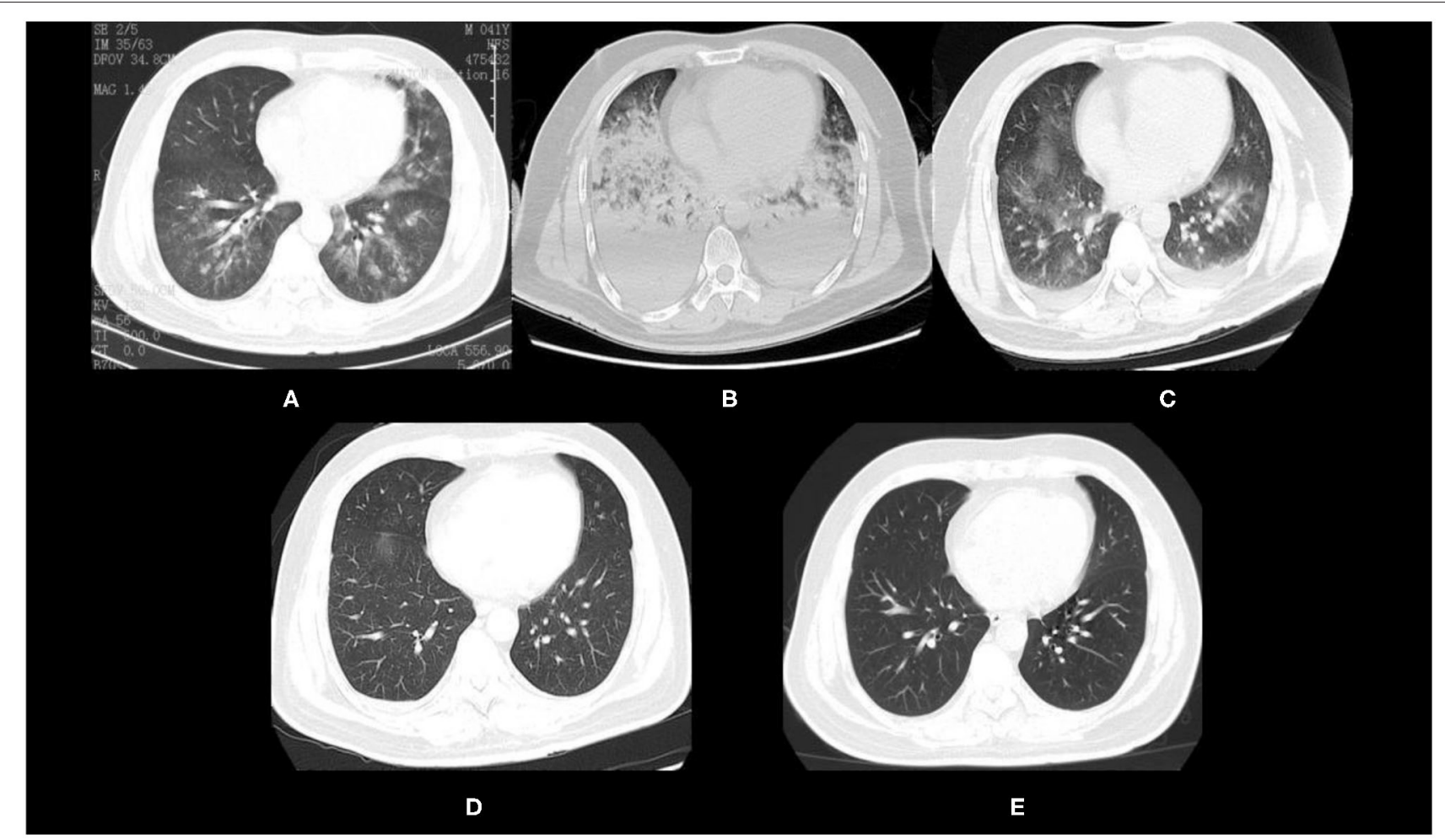

FIGURE 3 | Chest CT of the patient after mixed chemical gas inhalation. (A) Chest CT $2 \mathrm{~h}$ after inhalation. (B) Chest CT $20 \mathrm{~h}$ after ECMO initiation. (C) Chest CT after ECMO was weaned off. (D) Chest CT 2 days after weaning. (E) Chest CT 54 days after discharge.

function of the patient was normal 20 months later. The patient currently continues running and is said to have completed a full marathon recently.

\section{ECMO TECHNIQUES}

Extracorporeal membrane oxygenation, an auxiliary technique for respiratory and circulatory support, is increasingly being applied in clinical practice. ECMO drains the hypoxic blood from the venous system through the venous cannula. Then, the blood is oxygenated by a membrane oxygenator and pumped back to the patient through a second cannula $(9,25,26)$. There are two ECMO modalities; VV-ECMO and veno-arterial-ECMO (VAECMO). In VV-ECMO, the blood is drawn from the peripheral vein, often femoral vein, oxygenated and decarboxylated in a dedicated extracorporeal rotor/oxygenator device and pumped back to the right atrium through a cannula. However, VVECMO only provides respiratory support and is primarily used in $\operatorname{ARDS}$ patients $(9,26)$. In VA-ECMO, hypoxic blood is drawn from the vicinity of the right ventricle through a large bore cannula, which is usually percutaneously placed through the right jugular or femoral veins. The femoral vein is especially useful in emergency settings, for example, when cardiopulmonary resuscitation (CPR) is performed and chest compressions prevent proper, hygienic placement of the catheter through the right jugular vein. Then, the blood is pumped through the oxygenator and returned to the aorta via a large arterial catheter. VAECMO provides both respiratory and circulatory support and can be used in hemodynamically compromised patients. Therefore, ECMO is a potentially effective treatment modality for severely poisoned patients with severe ARDS and refractory cardiogenic shock or cardiac arrest.

\section{ECMO FOR ACUTE TOXIC INHALATION}

In toxicological studies, ECMO has shown positive effects in both the animal experiments and clinical cases. In the 1990s, this technique was found to significantly improve the survival of animals undergoing cardiac arrest after drug intoxication. Freedman et al. (16) reported that all lidocaine-induced cardiac arrest dogs survived through ECMO support, while the dogs treated with standard resuscitation had a mortality rate of $75 \%$. In recent years, ECMO has also achieved promising results for the treatment of chemical gas poisoning-induced cardiac arrest animals. Simonsen et al. (27) treated carbon monoxide (CO)-poisoned pigs with ECMO and conventional mechanical ventilation, and found that ECMO significantly reduced the incidences of cardiac arrest and mortality in CO-poisoned pigs, when compared with the conventional mechanical ventilation group. Furthermore, after sequential ECMO treatment, the survival rates of conventional mechanical ventilation group were found to have improved. In a previous study, the Danish scientists successfully cannulated and established VA-ECMO for $\mathrm{CO}$-induced cardiac arrest in the porcine models during airborne transportation (28). Although the animal study findings show that ECMO is effective in toxic gas-induced cardiovascular 
compromise, the experiments using these models are not the same as real clinical settings. Therefore, the role of ECMO in the treatment of acute toxic inhalation should be explored further in the clinical studies.

The animal model as well as human case reports and case series have shown that ECMO has favorable outcomes for acute toxic inhalation. Smoke is a common toxin that causes acute inhalation injuries and ARDS that requires ECMO support. The cases of ECMO support for fire-induced smoke inhalation injuries (29-35) and zinc chloride inhalation from smoke bombs have been reported (36). Electronic cigarettes (e-cigarettes) are battery-powered devices that aerosolize various substances for inhalation, such as nicotine, tetrahydrocannabinol, cannabidiol, and flavoring agents that may contain diacetyl. However, e-cigarettes should be evaluated further because they also cause pulmonary toxicity (37). As of November 13, 2019, a total of 2,172 "e-cigarette or vaping product use-associated lung injury" (EVALI) cases had been reported to the CDC of the Unites States, with 42 confirmed deaths (1). Landman et al. (38) reported a case of vaping-associated severe acute bronchiolitis, which caused near-fatal hypercapnic respiratory failure requiring intubation and ECMO in a 17-year-old male. The patient was weaned from VV-ECMO and ventilator, tracheostomy tube removed, and was discharged after 47 days in hospital. Accidental powder inhalation is a potential problem for infants. Panarello et al. (39) reported a case of severe ARDS due to accidental inhalation of rice starch powder in a 17-month-old girl. The girl was successfully treated with VV-ECMO. Metal fume inhalation also causes an acute respiratory and circulatory failure, and ECMO has been successfully applied for the severely poisoned patients $(40,41)$. Toxic gas inhalation causes lung damage. ECMO is a salvage therapy for inhaled toxic gases, such as, ammonia (42), hydrofluoric acid (43), hydrochlogen chloride (44), volatile hydrocarbons (45), carbon monoxide (46, 47), phosgene (48), chlorine (49-51), humidifier disinfectants (52), nitric and hydrofluoric acids (53, 54), and aluminum phosphide (55).

We report two cases of successful ECMO treatment for toxic volatile chemical inhalation. $\mathrm{Br}_{2}$, which is a reddishbrown fuming liquid with a unique odor and volatile at room temperature, is widely used as the raw material for the synthesis of pharmaceutical compounds, flame retardants, dyes, photographic chemicals, bleaches, and disinfectants. $\mathrm{Br}_{2}$ causes damage to the eyes, skin, central nervous system, and respiratory system (56-58). $\mathrm{Br}_{2}$ and hypobromous acid ( $\mathrm{HOBr}$ ), its hydrolysis product, are strong oxidants that initially react with antioxidants in the lung epithelial lining fluid after inhalation. The depletion of antioxidant stores promotes the reaction of $\mathrm{Br}_{2}$ and $\mathrm{HOBr}$ with plasma membranes of lung epithelial cells to form reactive intermediates, such as brominated lipids, which injure the distal sites. Moreover, $\mathrm{Br}_{2}$ inhalation promotes the intravascular hemolysis. The ensuing elevated free heme causes acute lung injury due to increased acute oxidative stress and inflammation in the lung tissues (59-61). During ECMO, we regularly monitored the hemoglobin levels, however, we did not observe intravascular hemolysis. Maybe, the heme levels could have been elevated, but the elevated level did not attract our attention. The inflammatory responses due to $\mathrm{Br}_{2}$ exposure worsens the initial pulmonary and systemic injuries, which in turn, aggravates the lung damage due to released inflammatory mediators. Inhalation of $\mathrm{Br}_{2}$ leads to various pulmonary symptoms, such as cough, dyspnea, hypoxia, or even death due to respiratory failure in the adults (56). There is no specific antidote for $\mathrm{Br}_{2}$ inhalation. Therefore, the first intervention step is to quickly move the patient out of the toxic environment, followed by the administration of appropriate therapies for symptomatic and supportive care, such as assisted ventilation, bronchodilators, and antibiotics. In our case, the patient was unresponsive to the conventional treatment, which prompted the initiation of ECMO for cardiopulmonary support. After 7 days of ECMO treatment, the condition of the patient improved and then, was successfully weaned off the treatment. To the best of our knowledge, this is the first reported case of successful ECMO treatment for $\mathrm{Br}_{2}$ inhalation-induced ARDS.

Nitric acid is a strong acid and an oxidizing agent for various applications. One of its main uses include the production of ammonium nitrate in the fertilizer industry and other industrial applications. Pure $\mathrm{HNO}_{3}$ is a colorless liquid with a boiling temperature of $84.1^{\circ} \mathrm{C}$ and can partially decompose to form nitrogen dioxide $\left(\mathrm{NO}_{2}\right)$. When exposed to air, pure $\mathrm{HNO}_{3}$ releases white fumes while $\mathrm{HNO}_{3}$ admixed with $\mathrm{NO}_{2}$ liberates reddish-brown vapors $(62,63)$. The applications of $\mathrm{HNO}_{3}$ generate various oxides of nitrogen, such as nitic oxide (NO), dinitrogen trioxide $\left(\mathrm{N}_{2} \mathrm{O}_{3}\right)$, dinitrogen tetroxide $\left(\mathrm{N}_{2} \mathrm{O}_{4}\right)$, and dinitrogen pentoxide $\left(\mathrm{N}_{2} \mathrm{O}_{5}\right)$ (63). The inhalation injuries attributed to $\mathrm{HNO}_{3}$ and its oxidized derivatives have been shown to cause acute local tissue inflammation within the lower respiratory tract (63). With regards to the human exposure, $\mathrm{NO}_{2}$ is the most important nitrogen oxide. Specific mechanisms leading to lung injury following $\mathrm{HNO}_{3}$ exposure have not been fully elucidated. However, it has been postulated that these injuries are due to a combination of free radical injuries, $\mathrm{NO}_{2}$ generation of nitric acid after mucosal membrane contact, decrease in $\alpha$-1-progease inhibitor, lipid peroxidation, thiol oxidation, and 3-nitrotyrosine formation (64). These deleterious effects lead to slough of tracheobronchial mucosa and are frequently accompanied by the direct toxic effects to the airways at the cellular level, which trigger the inflammatory cascade responses. The symptoms of $\mathrm{HNO}_{3}$ inhalation injury have been generalized into three phases, namely, acute, subacute, and delayed onset phases (63). In this study, acute exposure led to an immediate onset of chest tightness and shortness of breath. Subsequently, the patient presented with subacute symptoms, such as dyspnea and generalized weakness. Then, within $24 \mathrm{~h}$ after exposure, the patient quickly presented with delayed symptoms, such as dyspnea, tachypnea, bronchospasm, and cyanosis, which indicated pulmonary edema and ARDS. The symptomatic treatment of lung inhalation injury from $\mathrm{HNO}_{3}$ has been shown to be largely supportive, and it remains unstandardized (63). Kido et al. (65) reported a case of HNO3-induced pulmonary injury with improvement after corticosteroid administration. Meaden et al. (63) reported a case of pulmonary edema occurring after $\mathrm{HNO}_{3}$ inhalation, which improved after the bronchodilator treatment. We report the 
first case of successful ECMO treatment for ARDS after $\mathrm{HNO}_{3}$ inhalation, thereby, providing a new treatment modality for $\mathrm{HNO}_{3}$ inhalation-induced ARDS.

Of note, differences in the application of VV-ECMO for the management of toxic gas inhalation and other conditions should be noted. The patients with toxic gas inhalation are more prone to secondary infection and sepsis due to damage of the respiratory tract caused by the toxic gases compared with the patients with other ECMO indications. Therefore, monitoring body temperature, complete blood count, procalcitonin (PCT), and other infection indicators should be carried out during ECMO management. Full caloric and protein nutritional support are essential. High-dose, short-course methylprednisolone was administered in the early stages of both the cases. Although there was no evidence of reduced mortality, it improved the conditions of patients in our cases. In case 1, the patient was subjected to tracheostomy for laryngeal edema, therefore, the patient was at risk of infections. Appropriate antibiotics were administered to prevent the infections. Pharmacologic diuresis is important for edema clearance. In case 2, the patient was subjected to prone ventilation, which may have a positive effect on the rapid recovery from ARDS. The percutaneous cannulations were performed through the right femoral vein and the right internal jugular vein. Heparin was administered at the cannulation time and continuously infused during ECMO. Two patients were sedated. After the patient had stabilized on ECMO, all the sedatives and narcotics were stopped and resumed depending on the levels of anxiety and discomfort of the patient.

Although an increasing number of cases report the successful use of ECMO for acute toxic inhalations, evidence is majorly from the case reports and case series. We conclude that, when optimal conventional treatments fail, ECMO is a potential treatment modality for severe ARDS induced by acute toxic inhalations. However, large observational studies and randomized clinical trials should be conducted to support the effects of ECMO.

\section{INDICATIONS, CONTRAINDICATIONS, AND COMPLICATIONS FOR ECMO IN POISONED PATIENTS}

Extracorporeal membrane oxygenation provides effective gas exchange, reduces mechanical ventilation intensity, allows adequate lung rest, and improves patient outcomes. With the increasingly mature clinical applications of ECMO, there are many successful applications of ECMO in patients with irritant gas poisoning. ECMO improves the prognostic outcomes for severe hypoxemia and severe decompensated hypercapnia under optimal mechanical ventilation. Currently, this technique is a popular treatment option for medical toxicologists. However, it is not a standard treatment alternative as it lacks therapeutic evidence from large poisoning-based observational studies and randomized clinical trials. Indications for the poisoned patients are still under investigation. It has been recommended that ECMO can be initiated as soon as severely poisoned patients become unresponsive to optimal conventional interventions and have no contraindications for ECMO support.

\section{Indications}

Veno-venous-extracorporeal membrane oxygenation is recommended for respiratory failure when cardiac function is adequate or moderately depressed in the poisoned patients. It is also indicated for when the risk of mortality is greater than or equal to $80 \%$ (66). Approximately $80 \%$ mortality is associated with $\mathrm{PaO}_{2} / \mathrm{FiO}_{2}<100$ on $\mathrm{FiO}_{2}>90 \%$ and/or Murray score 3-4, age-adjusted oxygen index $(\mathrm{AOI})>80$, age, $\mathrm{PaO}_{2} / \mathrm{FiO}_{2}$ ratio, and plateau pressure (APSS) of eight despite optimal care for $6 \mathrm{~h}$ or less (66-69). VA-ECMO is recommended for poisoned patients with refractory cardiogenic shock or cardiac arrest and/or ARDS who are unresponsive to resuscitation, high-dose of vasopressors, transcutaneous cardiac pacing, and intra-aortic balloon pump (IABP), to provide cardiopulmonary support and maintain end-organ perfusion.

\section{Contraindications}

Few absolute contraindications for ECMO have been reported. They include severe irreversible non-cardiac organ failure limiting survival (e.g., severe anoxic brain injury or metastatic cancer), and irreversible cardiac failure if the transplantation or long-term ventricular assist devices are not considered (70). Moreover, ECMO treatment is absolutely contraindicated in the preexisting or acute conditions that are incompatible with recoveries, such as neurologic injury or end-stage malignancy that preclude a meaningful chance of intermediate-term survival or functional recovery (14). The relative contraindications for ECMO include severe coagulopathy or contraindications for systemic anticoagulation, such as advanced liver disease. Limited vascular access (severe peripheral arterial disease, extreme obesity, and amputated limbs), central as well as axillary cannulation are considered alternatives. Unrepaired aortic dissection, in which VA-ECMO flow may cause the additional fenestrations or propagate dissection flaps, should be cautiously performed, and acute aortic insufficiency that cannot be surgically corrected almost immediately is prohibited (14). Other relative contraindications include mechanical ventilation at high settings $\left(\mathrm{FiO}_{2}>90 \%\right.$, plateau pressure $\left.>30 \mathrm{cmH}_{2} \mathrm{O}\right)$ for 7 days or more and major pharmacologic immunosuppressions (absolute neutrophil count $<400 / \mathrm{mm}^{3}$ ). Even though the increasing age is associated with increased risks, no specific age contraindications have been reported (69).

\section{Complications}

Although ECMO has many clinical benefits, it also has notable complications. Severe potential complications include bleeding, thromboembolism, neurological injury, infection, limb ischemia, acute kidney injury, and homolysis (9, 14, 70-72).

\section{WEANING}

There is no universal method for determining whether ECMO can be successfully weaned and decannulated, however, some general principles apply. 
In VV-ECMO, ECMO flow is decreased in steps to $1 \mathrm{~L} / \mathrm{min}$ at sweep $\mathrm{FiO}_{2} 100 \%$ or decreased to $2 \mathrm{~L} / \mathrm{min}$, then sweep $\mathrm{FiO}_{2}$ is decreased to maintain $\mathrm{SaO}_{2}>95 \%$. When $\mathrm{SaO}_{2}$ is stable in these settings, trial off by adjusting the ventilator to lung protective ventilation settings (rate, plateau pressure, PEEP, and $\mathrm{FiO}_{2}$ ). Maintain blood flow and anticoagulation, stop the sweep gas, and cap off the oxygenator. If $\mathrm{SaO}_{2}>95 \%$ and $\mathrm{PaCO}_{2}<50$ $\mathrm{mmHg} \times 60 \mathrm{~min}$, the cannulas can be removed whenever the patient is ready, but ideally after heparin has been turned off for $30-60 \min (69)$.

In VA-ECMO, the first step is a holistic evaluation of the clinical status of the patient. Stable pulmonary status and euvolemia are particularly important (14). ECMO flow is decreased by approximately $1 \mathrm{~L} / \mathrm{h}$ over a period of $3-4 \mathrm{~h}$, although the slower rates of weaning at $0.5 \mathrm{~L}$ every $6-24 \mathrm{~h}$ have been reported $(70,73)$. The patient should be able to maintain mixed venous saturation $>65 \%$, and arterial saturation of $>90 \%$ with an ECMO flow $<1.5 \mathrm{~L} / \mathrm{min}$ (70). In case of decompensation signs, the bridge is clamped, and the patient is placed back on full support $(70,74)$.

\section{CONCLUSIONS}

An increasing number of successful ECMO treatment cases for acute toxic inhalations have been reported. However, the randomized clinical trials are needed to elucidate the

\section{REFERENCES}

1. Gummin DD, Mowry JB, Beuhler MC, Spyker DA, Brooks DE, Dibert KW, et al. 2019 Annual report of the american association of poison control centers' National Poison Data System (NPDS): 37th annual report. Clin Toxicol (Phila). (2020) 58:1360-541. doi: 10.1080/15563650.2020.1834219

2. Centers for Disease Control and Prevention. Web-based Injury Statistics Query and Reporting System (WISQARS) (2021). Available online at: http:// www.cdc.gov/injury/wisqars/fatal.html (accessed July 10, 2021).

3. Acute toxicity. International Union of Pure and Applied Chemistry (IUPAC) (2021). Available online at: https://goldbook.iupac.org/terms/view/AT06800 (accessed July 10, 2021).

4. Cowl CT. Assessment and treatment of acute toxic inhalations. Curr Opin Pulm Med. (2019) 25:211-6. doi: 10.1097/MCP.000000000000 0560

5. Gorguner M, Akgun M. Acute inhalation injury. Eurasian J Med. (2010) 42:28-35. doi: 10.5152/eajm.2010.09

6. National Occupational Exposure Survey (NOES 1981-1983) (1990). Available online at: https://www.cdc.gov/noes/ (accessed July 10, 2021).

7. Phua J, Badia JR, Adhikari NK, Friedrich JO, Fowler RA, Singh JM, et al. Has mortality from acute respiratory distress syndrome decreased over time? a systematic review. Am J Respir Crit Care Med. (2009) 179:2207. doi: $10.1164 / \mathrm{rccm} .200805-722 \mathrm{OC}$

8. Sud S, Friedrich JO, Taccone P, Polli F, Adhikari NK, Latini R, et al. Prone ventilation reduces mortality in patients with acute respiratory failure and severe hypoxemia: systematic review and meta-analysis. Intensive Care Med. (2010) 36:585-99. doi: 10.1007/s00134-009-1748-1

9. de Lange DW, Sikma MA, Meulenbelt J. Extracorporeal membrane oxygenation in the treatment of poisoned patients. Clin Toxicol (Phila). (2013) 51:385-93. doi: 10.3109/15563650.2013.800876

10. Zabrocki LA, Brogan TV, Statler KD, Poss WB, Rollins MD, Bratton SL. Extracorporeal membrane oxygenation for pediatric respiratory failure: survival and predictors of mortality. Crit Care Med. (2011) 39:36470. doi: 10.1097/CCM.0b013e3181fb7b35 survival benefits and to help develop the clinical guidelines and indications for ECMO initiation in acute poisoning. Although the evidence for the clinical applications of ECMO is mainly derived from the retrospective studies, case reports, and case series, we conclude that ECMO is a potential salvage therapy for severe ARDS and refractory cardiogenic shock or cardiac arrest induced by severe toxicological exposures. However, it should be noted that ECMO is a bridge to recovery, to a more durable bridge, to a definitive treatment, or to a better clinical decision, and is a powerful tool that should be used judiciously. Furthermore, all the caregivers involved in the poisoning treatment should be educated on the potentially lifesaving ECMO technology, its indications, complications, and weaning.

\section{AUTHOR CONTRIBUTIONS}

DY, ZL, and SJ conceptualized and wrote the manuscript. ZXL, PL, LF, ZL, and SJ treated the patient as described in this study. $\mathrm{ZL}$ and SJ revised the manuscript. All authors contributed to the article and approved the submitted version.

\section{FUNDING}

This study was financially supported by the Research Grant for Public Health Key Discipline of Shanghai Municipality, China (No. GWV-10.1-XK26).
11. Meltzer EC, Fins JJ. Extracorporeal membrane oxygenation for ARDS in adults. N Engl J Med. (2012) 366:575-6. doi: 10.1056/NEJMc1114604

12. Lawler PR, Silver DA, Scirica BM, Couper GS, Weinhouse GL, Jr., Camp PC. Extracorporeal membrane oxygenation in adults with cardiogenic shock. Circulation. (2015) 131:67680. doi: 10.1161/CIRCULATIONAHA.114.006647

13. Rao P, Khalpey Z, Smith R, Burkhoff D, Kociol RD. Venoarterial extracorporeal membrane oxygenation for cardiogenic shock and cardiac arrest. Circulation Heart failure. (2018) 11:e004905. doi: 10.1161/CIRCHEARTFAILURE.118.004905

14. Eckman PM, Katz JN, El Banayosy A, Bohula EA, Sun B, van Diepen S. Veno-arterial extracorporeal membrane oxygenation for cardiogenic shock: an introduction for the busy clinician. Circulation. (2019) 140:201937. doi: 10.1161/CIRCULATIONAHA.119.034512

15. Radowsky JS, Mazzeffi M.M, Deatrick KB, Galvagno SM, Parker BM, Tabatabai $\mathrm{A}$, et al. Intoxication and overdose should not preclude veno-venous extracorporeal membrane oxygenation. Perfusion. (2020). doi: 10.1177/0267659120963938. [Epub ahead of print].

16. Freedman MD, Gal J, Freed CR. Extracorporeal pump assistance-novel treatment for acute lidocaine poisoning. Eur J Clin Pharmacol. (1982) 22:12935. doi: 10.1007/BF00542457

17. Larkin GL, Graeber GM, Hollingsed MJ. Experimental amitriptyline poisoning: treatment of severe cardiovascular toxicity with cardiopulmonary bypass. Ann Emerg Med. (1994) 23:4806. doi: 10.1016/S0196-0644(94)70066-4

18. Weiner L, Mazzeffi MA, Hines EQ, Gordon D, Herr DL, Kim HK. Clinical utility of venoarterial-extracorporeal membrane oxygenation (VA-ECMO) in patients with drug-induced cardiogenic shock: a retrospective study of the Extracorporeal Life Support Organizations' ECMO case registry. Clin Toxicol (Phila). (2020) 58:705-10. doi: 10.1080/15563650.2019.1676896

19. Masson R, Colas V, Parienti JJ, Lehoux P, Massetti M, Charbonneau P, et al. A comparison of survival with and without extracorporeal life support treatment for severe poisoning due to drug intoxication. Resuscitation. (2012) 83:1413-7. doi: 10.1016/j.resuscitation.2012.03.028 
20. Lewis J, Zarate M, Tran S, Albertson T. The recommendation and use of extracorporeal membrane oxygenation (ECMO) in cases reported to the california poison control system. I Med Toxicol. (2019) 15:16977. doi: 10.1007/s13181-019-00704-3

21. Wang GS, Levitan R, Wiegand TJ, Lowry J, Schult RF, Yin S. Extracorporeal membrane oxygenation (ECMO) for severe toxicological exposures: review of the toxicology investigators consortium (ToxIC). J Med Toxicol. (2016) 12:95-9. doi: 10.1007/s13181-015-0486-8

22. Mégarbane B, Leprince P, Deye N, Résière D, Guerrier G, Rettab S, et al. Emergency feasibility in medical intensive care unit of extracorporeal life support for refractory cardiac arrest. Intensive Care Med. (2007) 33:75864. doi: 10.1007/s00134-007-0568-4

23. Rastan A.J., Dege A., Mohr M., Doll N., Falk V., Walther T., and Mohr F.W. Early and late outcomes of 517 consecutive adult patients treated with extracorporeal membrane oxygenation for refractory postcardiotomy cardiogenic shock. J Thoracic Cardiovasc Surg. (2010) 139:302-11.e1. doi: 10.1016/j.jtcvs.2009.10.043

24. Sayer GT, Baker JN, Parks KA. Heart rescue: the role of mechanical circulatory support in the management of severe refractory cardiogenic shock. Curr Opin Crit Care. (2012) 18:409-16. doi: 10.1097/MCC.0b013e328357fle6

25. Kulkarni T, Sharma NS, Diaz-Guzman E. Extracorporeal membrane oxygenation in adults: a practical guide for internists. Cleve Clin J Med. (2016) 83:373-84. doi: 10.3949/ccjm.83a.15021

26. Napp LC, Kühn C, Hoeper MM, Vogel-Claussen J, Haverich A, Schäfer A, et al. Cannulation strategies for percutaneous extracorporeal membrane oxygenation in adults. Clinic Res Cardiol. (2016) 105:283-96. doi: 10.1007/s00392-015-0941-1

27. Simonsen C, Magnusdottir SO, Andreasen JJ, Rohde MC, Kjærgaard B, ECMO. improves survival following cardiogenic shock due to carbon monoxide poisoning - an experimental porcine model. Scand J Trauma Resusc Emerg Med. (2018) 26:103. doi: 10.1186/s13049-018-0570-6

28. Simonsen C, Magnusdottir SO, Andreasen JJ, Bleeg RC, Lie C, Kjærgaard B. Long-distance transportation of carbon monoxide-poisoned patients on extracorporeal membrane oxygenation seems possible: a porcine feasibility study. Air Med J. (2019) 38:178-82. doi: 10.1016/j.amj.2019.03.009

29. Chiu YJ, Ma H, Liao WC, Shih YC, Chen MC, Shih CC, et al. Extracorporeal membrane oxygenation support may be a lifesaving modality in patients with burn and severe acute respiratory distress syndrome: Experience of Formosa Water Park dust explosion disaster in Taiwan. Burns. (2018) 44:11823. doi: 10.1016/j.burns.2017.06.013

30. Goretsky MJ, Greenhalgh DG, Warden GD, Ryckman FC, Warner BW. The use of extracorporeal life support in pediatric burn patients with respiratory failure. J Pediatr Surg. (1995) 30:620-3. doi: 10.1016/0022-3468(95)90145-0

31. McCunn M, Reynolds HN, Cottingham CA, Scalea TM, Habashi NM. Extracorporeal support in an adult with severe carbon monoxide poisoning and shock following smoke inhalation: a case report. Perfusion. (2000) 15:16973. doi: $10.1177 / 026765910001500213$

32. Nelson J, Cairns B, Charles A. Early extracorporeal life support as rescue therapy for severe acute respiratory distress syndrome after inhalation injury. J Burn Care Res. (2009) 30:1035-8. doi: 10.1097/BCR.0b013e3181bfb7fd

33. Thompson JT, Molnar JA, Hines MH, Chang MC, Pranikoff T. Successful management of adult smoke inhalation with extracorporeal membrane oxygenation. J Burn Care Rehabil. (2005) 26:62-6. doi: 10.1097/01.BCR.0000150303.15345.79

34. Dadras M, Wagner JM, Wallner C, Huber J, Buchwald D, Strauch J, et al. Extracorporeal membrane oxygenation for acute respiratory distress syndrome in burn patients: a case series and literature update. Burns Trauma. (2019) 7:28. doi: 10.1186/s41038-019-0166-Z

35. Lessin MS, el-Eid SE, Klein MD, Cullen ML. Extracorporeal membrane oxygenation in pediatric respiratory failure secondary to smoke inhalation injury. J Pediatric Surg. (1996) 31:12857. doi: 10.1016/S0022-3468(96)90252-3

36. Chian CF, Wu CP, Chen CW, Su WL, Yeh CB, Perng WC. Acute respiratory distress syndrome after zinc chloride inhalation: survival after extracorporeal life support and corticosteroid treatment. Am J Crit Care. (2010) 19:8690. doi: 10.4037/ajcc2009908

37. National Center for Chronic Disease Prevention and Health Promotion (US) Office on Smoking and Health. E-Cigarette Use Among Youth and Young
Adults: A Report of the Surgeon General. Atlanta (GA): Centers for Disease Control and Prevention (US). (2016).

38. Landman ST, Dhaliwal I, Mackenzie CA, Martinu T, Steele A, Bosma KJ. Life-threatening bronchiolitis related to electronic cigarette use in a Canadian youth. CMAJ. (2019) 191:E1321-e1331. doi: 10.1503/cmaj.191402

39. Panarello G, Occhipinti G, Piazza M, Capitanio G, Vitulo P, Gridelli B, et al. Severe acute respiratory failure due to inhalation of baby powder and successfully treated with venous-venous extracorporeal membrane oxygenation. A \& A Case Reports. (2015) 5:228-30. doi: 10.1213/XAA.0000000000000236

40. Ahn H.J., Lee J.W., Ryu S., Cho Y.C., and Jeong W.J. Refractory hypoxemic respiratory failure from metal fume inhalation: Emergency department procedures. Am J Emerg Med. (2017) 35:809.e1-e3. doi: 10.1016/j.ajem.2016.12.025

41. Rahimzadeh MR, Rahimzadeh MR, Kazemi S, Moghadamnia AA. Zinc poisoning - symptoms, causes, treatments. Mini Rev Med Chem. (2020) 20:1489-98. doi: 10.2174/1389557520666200414161944

42. $\mathrm{Lu} \mathrm{H}$, Liu Q, Lan C. Application of extracorporeal membrane oxygenation technique in patients with acute respiratory failure caused by ammonia poisoning. Chin Crit Care Med. (2019) 31:1542-4. doi: 10.3760/cma.j.issn.2095-4352.2019.12.022

43. Ma J, Deng JJ, Wu J, Lu RN. Research advances on the diagnosis and treatment of hydrofluoric acid inhalation injury. Chin J Burns. (2020) 36:9758. doi: 10.3760/cma.j.cn501120-20191030-00420

44. Xia ML, Lou YF, Ma WJ. Clinical analysis of 5 cases of acute poisoning by inhalation of hydrochlogen chloride. Chin J Ind Hygiene Occup Dis. (2019) 37:855-7. doi: 10.3760/cma.j.issn.1001-9391.2019.11.015

45. Möller JC, Vardag AM, Jonas S, Tegtmeyer FK. Poisoning with volatile hydrocarbons. 3 cases and a review. Monatsschrift Kinderheilkunde. (1992) 140:113-6

46. Baran DA, Stelling K, McQueen D, Pearson M, Shah V. Pediatric veno-veno extracorporeal membrane oxygenation rescue from carbon monoxide poisoning. Pediatr Emerg Care. (2020) 36:e592-4. doi: $10.1097 /$ pec.0000000000001486

47. Teerapuncharoen K, Sharma NS, Barker AB, Wille KM, Diaz-Guzman E. Successful treatment of severe carbon monoxide poisoning and refractory shock using extracorporeal membrane oxygenation. Respir Care. (2015) 60:e155-60. doi: 10.4187/respcare.03990

48. He Z, Yang X, Yang C. Extracorporeal membrane oxygenation for acute respiratory distress syndrome caused by acute phosgene poisoning: a report of 4 cases. Chin Crit Care Med. (2019) 31:232-5. doi: 10.3760/cma.j.issn.2095-4352.2019.02.022

49. Mangat HS, Stewart TL, Dibden L, Tredget EE. Complications of chlorine inhalation in a pediatric chemical burn patient: a case report. J Burn Care Res. (2012) 33:e216-21. doi: 10.1097/BCR.0b013e318254d1c8

50. Harischandra T, Withanaarachchi K, Piyasiri B, Wickramasuriya H, Piyasiri G, Firmin R. Successful use of extracorporeal membrane oxygenation in acute respiratory distress syndrome following accidental chlorine gas inhalation at a swimming pool. Perfusion. (2020) 35:543-5. doi: 10.1177/0267659120922013

51. Zhao H, Shu J, Li RF. One case of acute respiratory distress syndrome induced by chlorine inhalation treated by combining extracorporeal membrane oxygenation and blood purification. Chin J Ind Hygiene Occup Dis. (2017) 35:312-3. doi: 10.3760/cma.j.issn.1001-9391.2017.04.024

52. Jhang WK, Park SJ, Lee E, Yang SI, Hong SJ, Seo JH, et al. The first successful heart-lung transplant in a korean child with humidifier disinfectant-associated interstitial lung disease. J Korean Med Sci. (2016) 31:817-21. doi: 10.3346/jkms.2016.31.5.817

53. Shin JS, Lee SW, Kim NH, Park JS, Kim KJ, Choi SH, et al. Successful extracorporeal life support after potentially fatal pulmonary oedema caused by inhalation of nitric and hydrofluoric acid fumes. Resuscitation. (2007) 75:184-8. doi: 10.1016/j.resuscitation.2007. 04.004

54. Pu Q., Qian J., Tao W., Yang A., Wu J., and Wang Y. Extracorporeal membrane oxygenation combined with continuous renal replacement therapy in cutaneous burn and inhalation injury caused by hydrofluoric acid and nitric acid. Medicine (2017) 96. doi: 10.1097/MD.0000000000008972

55. Hena Z, McCabe ME, Perez MM, Sharma M, Sutton NJ, Peek GJ, et al. Aluminum phosphide poisoning: Successful recovery of multiorgan failure 
in a pediatric patient. Int J Pediatrics Adolescent Med. (2018) 5:1558. doi: 10.1016/j.ijpam.2018.09.001

56. Woolf A, Shannon M. Reactive airways dysfunction and systemic complaints after mass exposure to bromine. Environ Health Perspect. (1999) 107:5079. doi: 10.1289/ehp.99107507

57. Rogers JV, Price JA, Wendling MQ, Perry MR, Reid FM, Kiser RC, et al. An assessment of transcriptional changes in porcine skin exposed to bromine vapor. J Biochem Mol Toxicol. (2011) 25:252-62. doi: 10.1002/jbt.20383

58. Lam A, Vetal N, Matalon S, Aggarwal S. Role of heme in bromine-induced lung injury. Ann N Y Acad Sci. (2016) 1374:105-10. doi: 10.1111/nyas.13086

59. Wagener FA, Eggert A, Boerman OC, Oyen WJ, Verhofstad A, Abraham NG, et al. Heme is a potent inducer of inflammation in mice and is counteracted by heme oxygenase. Blood. (2001) 98:1802-11. doi: 10.1182/blood.V98.6.1802

60. Ryter SW, Tyrrell RM. The heme synthesis and degradation pathways: role in oxidant sensitivity. Heme oxygenase has both pro- and antioxidant properties/ Free Radical Biol Med. (2000) 28:289-309. doi: 10.1016/S0891-5849(99)00223-3

61. Gutteridge JM, Smith A. Antioxidant protection by haemopexin of haem-stimulated lipid peroxidation. Biochem J. (1988) 256:861-5. doi: 10.1042/bj2560861

62. Murphy CM, Akbarnia H, Rose SR. Fatal pulmonary edema after acute occupational exposure to nitric acid. J Emerg Med. (2010) 39:3943. doi: 10.1016/j.jemermed.2008.03.011

63. Meaden CW, Kashani JS, Vetrano S. Pulmonary edema occurring after nitric acid exposure. Case Rep Emerg Med. (2019) 2019:9303170. doi: 10.1155/2019/9303170

64. Persinger R.L., Poynter M.E., Ckless K., and Janssen-Heininger Y.M. Molecular mechanisms of nitrogen dioxide induced epithelial injury in the lung. Mol Cell Biochem (2002) 234-235: 71-80. doi: 10.1023/A:1015973530559

65. Kido Y, Mitani A, Isago H, Takeshima H, Narumoto O, Tanaka G, et al. Successful treatment of pulmonary injury after nitrogen oxide exposure with corticosteroid therapy: A case report and review of the literature. Respir Med Case Rep. (2017) 20:107-10. doi: 10.1016/j.rmcr.2017.01.007

66. Patel AR, Patel AR, Singh S, Singh S, Munn NJ. Venovenous extracorporeal membrane oxygenation therapy in adults. Cureus. (2019) 11:e5365. doi: 10.7759/cureus.5365

67. Dechert RE, Park PK, Bartlett RH. Evaluation of the oxygenation index in adult respiratory failure. J Trauma Acute Care Surg. (2014) 76:46973. doi: 10.1097/TA.0b013e3182ab0d27

68. Villar J, Ambrós A, Soler JA, Martínez D, Ferrando C, Solano R. et al. Age, $\mathrm{Pao} 2 / \mathrm{Fio} 2$, and plateau pressure score: a proposal for a simple outcome score in patients with the acute respiratory distress syndrome. Crit Care Med. (2016) 44:1361-9. doi: 10.1097/CCM.0000000000001653

69. Extracorporeal Life Support Organization ELSO Guidelines (2021). https:// www.elso.org/Resources/Guidelines.aspx (accessed July 5, 2021).

70. Guglin M, Zucker MJ, Bazan VM, Bozkurt B, El Banayosy A, Estep JD, et al. Venoarterial ECMO for adults: JACC scientific expert panel. J Am Coll Cardiol. (2019) 73:698-716. doi: 10.1016/j.jacc.2018.11.038

71. Mateen FJ, Muralidharan R, Shinohara RT, Parisi JE, Schears GJ, Wijdicks EF. Neurological injury in adults treated with extracorporeal membrane oxygenation. Arch Neurol. (2011) 68:1543-9. doi: 10.1001/archneurol.2011.209

72. Cheng R, Hachamovitch R, Kittleson M, Patel J, Arabia F, Moriguchi J, et al. Complications of extracorporeal membrane oxygenation for treatment of cardiogenic shock and cardiac arrest: a meta-analysis of 1,866 adult patients. Ann Thorac Surg. (2014) 97:610-6. doi: 10.1016/j.athoracsur.2013.09.008

73. Stub D, Bernard S, Pellegrino V, Smith K, Walker T, Sheldrake J, et al. Refractory cardiac arrest treated with mechanical CPR, hypothermia, ECMO and early reperfusion (the CHEER trial). Resuscitation. (2015) 86:88-94. doi: 10.1016/j.resuscitation.2014.09.010

74. Vida VL, Lo Rito M, Padalino MA, Stellin G. Extracorporeal membrane oxygenation: the simplified weaning bridge. J Thorac Cardiovasc Surg. (2012) 143:e27-8. doi: 10.1016/j.jtcvs.2011.12.065

Conflict of Interest: The authors declare that the research was conducted in the absence of any commercial or financial relationships that could be construed as a potential conflict of interest.

Publisher's Note: All claims expressed in this article are solely those of the authors and do not necessarily represent those of their affiliated organizations, or those of the publisher, the editors and the reviewers. Any product that may be evaluated in this article, or claim that may be made by its manufacturer, is not guaranteed or endorsed by the publisher.

Copyright (C) 2021 Yu, Xiaolin, Lei, Feng, Lin and Jie. This is an open-access article distributed under the terms of the Creative Commons Attribution License (CC BY). The use, distribution or reproduction in other forums is permitted, provided the original author(s) and the copyright owner(s) are credited and that the original publication in this journal is cited, in accordance with accepted academic practice. No use, distribution or reproduction is permitted which does not comply with these terms. 